\title{
Letters
}

\section{Insulin-mediated vasodilation: why one's physiology could be the other's pharmacology}

\section{Dear Sir,}

We read with great interest the review by Utriainen and YkiJarvinen [1] entitled "Insulin-induced vasodilation: physiology or pharmacology." Because the "review" reads like an opinion, we decided to offer ours. The divergent findings regarding insulin's vascular effects illustrate a classic case, where carefully collected data by separate laboratories addressing the same question can result in opposite findings and interpretations. In such cases, it is best to consider all data as valid and accurate within the context in which they were derived. With time, resolution of the controversy usually occurs through independent confirmation and new methodologies.

Ten years ago, we reported that insulin causes a physiologic dose dependent skeletal muscle vasodilation, that this insulin action is impaired in insulin resistant states, and that insulin mediated vasodilation and rates of glucose metabolism were highly correlated, suggesting a tight coupling between these two variables [2]. These reports initiated a controversy. Two questions lay at the heart of it: 1) whether insulin mediated vasodilation is physiologic and 2) whether it contributes to overall insulin mediated glucose uptake (insulin sensitivity).

The argument made against insulin's physiologic role to augment skeletal muscle perfusion is largely based on studies using plethysmography. Plethysmography has a coefficient of variation of about $40 \%$ [3]. Describing a biologic system with an insensitive method will cause a spurious right shift in both the dose and time response curves, i.e. turning physiology into pharmacology. Perhaps this explains the perplexing fact that insulin mediated vasodilation was not observed earlier. Why this finding has subsequently been confirmed by many [4], in some cases by the very same workers who previously had been unable to observe it, is not clear. For example, using plethysmography, Dr. Yki-Jarvinen first reported no vasodilation after 90 min of hyperinsulinaemia [5] (10200 pmol/l) but later observed it at much lower insulin concentrations (420 $\mathrm{pmol} / \mathrm{l})[6]$.

The ability of positron emission tomography (PET) to measure skeletal muscle blood flow [7] or insulin stimulated glucose uptake have not been validated. Importantly, studies from Kelley [8] indicate that this tomography possibly underestimates true rates of insulin stimulated leg glucose uptake by about $50 \%$, which is similar to the error found in the heart [9]. This large error is likely due to the flawed assumption

Corresponding author: A.D. Baron, Indiana University School of Medicine, Division of Endocrinology and Metabolism, Department of Medicine, 541 North Clinical Drive, CL 459, Indianapolis, IN 46202-5111, USA that the lump constant for [18]fluoro-2-deoxy-glucose does not change with insulin stimulation or insulin resistance. To unequivocally conclude from positron emission tomography studies that insulin mediated vasodilation is not instrumental in modulating glucose uptake, it is critical to know its limits of detection. By the combined use of the euglycaemic hyperinsulinaemic clamp, limb balance technique and L-N-monomethylarginine (L-NMMA) to inhibit increments in leg blood flow, we have shown that insulin mediated blood flow accounts for about $30 \%$ of insulin's overall effect to stimulate leg glucose uptake [10]. Of note, this particular experimental design, which uniquely shows this insulin effect, has yet to be used by others, which could explain why our findings have not been reproduced.

Dr. Yki-Jarvinen's group actually provided direct support for the idea that vasodilation (with enhanced microcirculatory nutritive flow) contributes to enhanced insulin mediated glucose uptake. They reported that areas of skeletal muscle exhibiting the highest rates of blood flow also exhibit the highest rates of glucose uptake [11], supporting the notion of coupling between vasodilation and glucose metabolism. Furthermore, Drs. Utriainen and Yki-Jarvinen state that insulin mediated vasodilation becomes rate limiting to glucose uptake at very high insulin concentrations when glucose extraction is at a maximum and flow begins to increase. Based on this line of reasoning, it is interesting to consider how Drs. Utriainen and Yki-Jarvinen would interpret their data if it showed a physiological effect of insulin on blood flow - undoubtedly not any differently than the way we have interpreted it, namely that insulin mediated vasodilation occurs under physiological conditions and contributes significantly to insulin mediated glucose uptake [10].

Yours sincerely,

H.O. Steinberg, A. D. Baron

\section{References}

1. Yki-Jarvinen H, Utriainen $T$ (1998) Insulin-induced vasodilation: physiology or pharmacology? Diabetologia 41: 369-379

2. Baron AD (1993) Cardiovascular actions of insulin in humans. Implications for insulin sensitivity and vascular tone. Baillieres Clin Endocrinol Metabol 7: 962-987

3. Petrie JR, Ueda S, Morris AD, Murray LS, Elliott HL, Connell JMC (1998) How reproducible is bilateral forearm plethysmography? Br J Clin Pharmacol 45: 131-139

4. Scherrer U, Sartorio C (1997) Insulin as a vascular and sympathoexcitory hormone: Implications for blood pressure regulation, insulin sensitivity, and cardiovascular mortality. Circulation 96: 4104-4113

5. Yki-Jarvinen H, Young AA, Lamkin C, Foley JE (1987) Kinetics of glucose disposal in whole body and across the forearm in man. J Clin Invest 79: 1713-1719 
6. Utriainen T, Makimattila S, Virkamaki A, Bergholm R, Yki-Jarvinen H (1996) Dissociation between insulin sensitivity of glucose uptake and endothelial function in normal subjects. Diabetologia 39 (12): 1477-1482

7. Vicini P, Bonadonna RC, Utriainen T, Nuutila P, Raitakari M, Yki-Jarvinen H, Cobelli C (1997) Estimation of blood flow heterogeneity distribution in human skeletal muscle from positron emission tomography data. Ann Biomed Eng 25 (5): 906-910

8. Kelley D, Price J, Beattie J, Goodpaster S, Andreko SJ, Jedali F (1997) Analog effects of FDG in human skeletal muscle: physiologic implications of insulin induced reductions of "LC". Diabetologia 40 [Suppl 1]: A4
9. Doenst T, Taegtmeyer H (1998) Profound underestimation of glucose uptake by [18F]2-deoxy-2-fluoroglucose in reperfused rat heart muscle. Circulation 97: 2454-2462

10. Baron AD, Brechtel-Hook G, Johnson A, Cronin J, Leaming R, Steinberg HO (1996) Effect of perfusion rate on the time course of insulin mediated skeletal muscle glucose uptake. Am J Physiol 271: E1067-E1072

11. Utriainen T, Nuutila P, Takala T et al. (1997) Intact insulin stimulation of skeletal muscle blood flow, its heterogeneity and redistribution, but not of glucose uptake in non-insulin-dependent diabetes mellitus. J Clin Invest 100: 777-785

\section{Insulin-mediated vasodilatation: the authors' reply}

\section{Dear Sir,}

We thank Steinberg and Baron for their comments on our review [1]. It is disappointing that the most important message of the review has been missed.

The major difference between the studies by Steinberg and Baron, and those by other investigators is in the design used to study insulin's effect on limb blood flow. In the first study describing a 'physiologic' dose-dependent effect of insulin on limb blood flow in 1990, insulin was infused sequentially in increasing doses for $9 \mathrm{~h}$ (ref. 8 in [1]). Between 5 and $7 \mathrm{~h}$ of insulin infusion, a $40 \%$ increase in blood flow was observed. At $9 \mathrm{~h}$ at an insulin concentration of $17520 \mathrm{pmol} / \mathrm{l}$, flow had increased by $65 \%$ ( $4.3 \mathrm{vs} 2.6 \mathrm{dl} / \mathrm{min})$. These data do not differ from those reported by ourselves using sequential insulin infusions and measurement of forearm blood flow using plethysmography (reproducibility appears to be laboratory-dependent, in our laboratory it is $13 \%$, ref. 19 in [1]): an increase in flow of $50 \%$ at $4 \mathrm{~h}$ (insulin $834 \mathrm{pmol} / \mathrm{l}$ ) and $113 \%$ at $6 \mathrm{~h}$ (insulin $2907 \mathrm{pmol} / \mathrm{l}$ ). The difference between this study and our earlier study cited by Steinberg and Baron [2] is that in the latter study various doses of insulin were infused on separate days rather than sequentially and that basal and insulin stimulated flows were determined in different groups of subjects. After an oral glucose tolerance test in normal middle-aged subjects, insulin concentrations increase to a mean peak concentration of $360 \mathrm{pmol} / \mathrm{l}$ after $1 \mathrm{~h}$ and return to baseline by $3 \mathrm{~h}$ [3]. In our view, the latter conditions represent physiology. In the review, we analysed data from 75 studies just in normal subjects and showed that under conditions we consider physiological (dose * duration of insulin infusion $<1$, Fig. 2 in [1]), blood flow was unchanged. Taken together these data indicate that the duration of the insulin infusion rather than the method is the most important determinant of the blood flow response to insulin. Along the same lines, even investigators using the same technique as Steinberg and Baron (ref.11 in [1]) or different techniques (refs.12, 71-74 in [1]), have failed to find a defect in insulin stimulated blood flow in patients with Type II (non-insulin-dependent) diabetes mellitus. This again shows that results regarding flow are not technique-dependent. The discrepant data might be explained by factors such as limb muscularity and muscle capillary density (refs. 19 and 26 in [1]), which explain more than $70 \%$ of interin-

Corresponding author: Dr. H. Yki-Järvinen, Department of Medicine, Division of Endocrinology and Diabetes, University of Helsinki, Haartmaninkatu 4, FN-00029 Huch, Finland dividual variation in basal flow and of flow responses to insulin measured with plethysmography. The latter data further support the validity of the technique.

Regarding the question of whether insulin-mediated vasodilatation contributes to glucose uptake, we would agree that resolution of controversy occurs through independent confirmation and new methodologies. In this respect, the authors correctly observe that their finding of a change in glucose uptake in response to a change in flow has not been reproduced in 3 studies cited in the review (refs. 80, 82, 83 in [1]) or in 3 subsequent studies [4-6]. How many repeated attempts do we need? The flow intervention studies include our studies where positron emission tomography (PET), $\left[{ }^{15} \mathrm{O}\right]-\mathrm{H}_{2} \mathrm{O}$ and the autoradiographic method has been used to measure blood flow directly in skeletal muscle. Steinberg and Baron appear to have missed validation of this method [7]. Regarding the ability of $\left.{ }^{[18} \mathrm{F}\right]-$ FDG and PET to accurately trace glucose uptake in skeletal muscle, again the statement of lack of validation is simply scientifically unfounded. The validation includes comparison of PET measurements with traditional measurements using the Fick principle [8] and direct determination of the lumped constant in the presence and absence of insulin in human skeletal muscle (ref. [9]). In our experience, the regression equation relating muscle glucose uptake measured with PET in any group of subjects [normal men and women, obese, hypertensive and Type I (insulin-dependent) and II diabetic patients] is close to that measured independently with the euglycaemic clamp technique and reproducible. This technique also offers the unique possibility to measure glucose uptake without invasive femoral artery and vein catheterizations anywhere in skeletal muscle. We do not understand why Steinberg and Baron consider these human data in skeletal muscle invalid because of strange results obtained in the isolated perfused rat heart preparation. In support of the peculiarities of the former preparation, $\left[{ }^{18} \mathrm{~F}\right]-\mathrm{FDG}$ has recently been shown to accurately trace glucose metabolism even in the human heart in vivo both under fasting and various insulin stimulated conditions [10].

In conclusion, we do not regard the data of Steinberg and Baron to be inconsistent with data generated by other investigators, when the multiple aspects listed in the review, especially the time-dependency of the phenomenon, are carefully considered. The only discrepancy seems to be confined to studies examining whether glucose uptake can be altered by changing blood flow. In any event, we believe the time has come to proceed from trying to explain muscle glucose uptake with blood flow changes induced by insulin to clinically more relevant questions such as why blood vessels stiffen and develop atherosclerosis in insulin resistant people.

Yours sincerely,

H. Yki-Järvinen, T. Utriainen 